\title{
Thermal Performance of ATLAS Laser Thermal Control System Demonstration Unit
}

\author{
Jentung $\mathrm{Ku}^{1}{ }^{\text {, Franklin Robinson }}{ }^{2}$, Deepak Patel ${ }^{3}$ and Laura Ottenstein. ${ }^{4}$ \\ NASA Goddard Space Flight Center, Greenbelt, MD 20771
}

The second Ice, Cloud, and Land Elevation Satellite mission currently planned by National Aeronautics and Space Administration will measure global ice topography and canopy height using the Advanced Topographic Laser Altimeter System (ATLAS). The ATLAS comprises two lasers; but only one will be used at a time. Each laser will generate between $125 \mathrm{~W}$ and $250 \mathrm{~W}$ of heat, and each laser has its own optimal operating temperature that must be maintained within $\pm 1^{\circ} \mathrm{C}$ accuracy by the Laser Thermal Control System (LTCS) consisting of a constant conductance heat pipe (CCHP), a loop heat pipe (LHP) and a radiator. The heat generated by the laser is acquired by the CCHP and transferred to the LHP, which delivers the heat to the radiator for ultimate rejection. The radiator can be exposed to temperatures between $-71^{\circ} \mathrm{C} \mathrm{and}-93^{\circ} \mathrm{C}$. The two Iasers can have different operating temperatures varying between $+15^{\circ} \mathrm{C}$ and $+30^{\circ} \mathrm{C}$, and their operating temperatures are not known while the LTCS is being designed and built. Major challenges of the LTCS include: 1) A single thermal control system must maintain the ATLAS at $15{ }^{\circ} \mathrm{C}$ with $250 \mathrm{~W}$ heat load and $-71{ }^{\circ} \mathrm{C}$ radiator sink temperature, and maintain the ATLAS at $+30^{\circ} \mathrm{C}$ with $125 \mathrm{~W}$ heat load and $-93^{\circ} \mathrm{C}$ radiator sink temperature. Furthermore, the LTCS must be qualification tested to maintain the ATLAS between $+10^{\circ} \mathrm{C}$ and $+35^{\circ} \mathrm{C}$. 2) The LTCS must be shut down to ensure that the ATLAS can be maintained above its lowest desirable temperature of $-2{ }^{\circ} \mathrm{C}$ during the survival mode. No software control algorithm for LTCS can be activated during survival and only thermostats can be used. 3) The radiator must be kept above $-65^{\circ} \mathrm{C}$ to prevent ammonia from freezing using no more than $135 \mathrm{~W}$ of heater power. 4 ) The LHP reservoir control heater power is limited to $15 \mathrm{~W}$ with a $70 \%$ duty cycle. 5 ) The voltage of the power supply can vary between $26 \mathrm{Vdc}$ and $34 \mathrm{Vdc}$ during the spacecraft lifetime. A design analysis shows that a single LTCS can satisfy these requirements. However, shutdown of the LHP is particularly challenging and the shutdown heater must be wired in series with two reservoir thermostats and two CCHP thermostats at different set points. An LTCS demonstration unit has been tested to verify these performance characteristics experimentally prior to proceeding to the final LTCS design and fabrication. Test results showed that the LHP shutdown scheme would be able to shut down the LHP as designed and the reservoir control heater can maintain the ATLAS mass simulator within the $\pm 1^{\circ} \mathrm{C}$ accuracy under various combinations of the heat load, sink temperature, and power supply voltage.

$\begin{array}{ll}\text { ATLAS } & \text { Nomenclature } \\ C C & =\text { Advanced Topographic Laser Altimeter System } \\ C C H P & =\text { Compensation Chamber } \\ \text { GSFC } & =\text { Goddard Space Flight Center } \\ \text { ICESat } & =\text { Ice, Cloud, and Land Elevation Satellite } \\ \text { LHP } & =\text { Loop Heat Pipe } \\ \text { LTCS } & =\text { Laser Thermal Control System } \\ \text { NASA } & =\text { National Aeronautics and Space Administration }\end{array}$

I. Introduction

THE second Ice, Cloud, and Land Elevation Satellite (ICESat-2) mission currently planned by the National 1 Aeronautics and Space Administration (NASA) will measure global ice topography and canopy height. The

\footnotetext{
${ }^{1}$ Laboratory Manager, Thermal Engineering Branch, Goddard Space Flight Center, Greenbelt, Maryland, USA, AiAA Senior Member.

${ }^{2}$ Aerospace Engineer, Thermal Engineering Branch, Goddard Space Flight Center, Greenbelt, Maryland, USA

${ }^{3}$ Aerospace Engineer, Thermal Engineering Branch, Goddard Space Flight Center, Greenbelt, Maryland, USA

${ }^{4}$ Aerospace Engineer, Thermal Engineering Branch, Goddard Space Flight Center, Greenbelt, Maryland, USA 1
} 
mission requires a micropulse space flight laser system, called Advanced Topographic Laser Altimeter System (ATLAS). The ATLAS comprises two lasers; but only one will be used at a time. Each laser will generate between $125 \mathrm{~W}$ and $250 \mathrm{~W}$ of heat during its operation, and each laser has its own optimal operating temperature that must be maintained within $\pm 11^{\circ} \mathrm{C}$ accuracy by the Laser Thermal Control System (LTCS) consisting of a constant conductance heat pipe (CCHP) and a loop heat pipe (LHP) with an associated radiator as shown in Figure 1. The CCHP is attached to the two lasers at its evaporator end, and to the LHP evaporator at its condenser end. Thus, heat generated by the lasers is acquired by the CCHP and transferred to the LHP, which delivers the heat to the radiator for ultimate rejection to space. Both the CCHP and LHP use ammonia as the working fluid. The CCHP and LHP are versatile capillary two-phase heat transfer devices which can transport large amounts of heat over long distances with very small temperature differences [1-4]. In addition, the LHP can provide very tight temperature control for instruments $[5,6]$. Both CCHPs and LHPs have extensive flight heritage: CCHPs are used in almost every contemporary satellite, and LHPs are used in many NASA spacecraft and commercial satellites [7-13].

The ATLAS LTCS radiator can be exposed to a thermal environment whose temperature varies between $-71^{\circ} \mathrm{C}$ and $-93^{\circ} \mathrm{C}$. The radiator must be sized so that it can reject the maximum heat at the highest sink temperature. However, such a radiator will become oversized at the minimum heat load and minimum sink temperature, which affects the control heater power required by the LHP reservoir (also known as the compensation chamber or $\mathrm{CC}$ ) and the survival heater power required by the radiator. What is unusual for the ATLAS LTCS design is that a single thermal control device must maintain the two lasers at their optimal operating temperatures which can vary from $+15^{\circ} \mathrm{C}$ to $+30^{\circ} \mathrm{C}$, and the optimal operating temperatures are not known until after the LTCS has been designed and manufactured. Furthermore, NASA's design guide requires the two-phase LTCS be qualification tested to demonstrate its ability to maintain the ATLAS temperature between $+10^{\circ} \mathrm{C}$ and $+35^{\circ} \mathrm{C}$, as summarized in Table 1 . Specifically, the LTCS must be able to maintain the ATLAS at $+10^{\circ} \mathrm{C}$ with a heat load of $250 \mathrm{~W}$ and a radiator sink temperature of $-71^{\circ} \mathrm{C}$, and maintain the ATLAS at $+35^{\circ} \mathrm{C}$ with a heat load of $125 \mathrm{~W}$ and a radiator sink temperature of $-93^{\circ} \mathrm{C}$. In addition, the radiator must be kept above $-65^{\circ} \mathrm{C}$ to prevent ammonia from freezing using no more than $135 \mathrm{~W}$ of radiator survival heater power, and the LHP reservoir control heater power is limited to $15 \mathrm{~W}$.

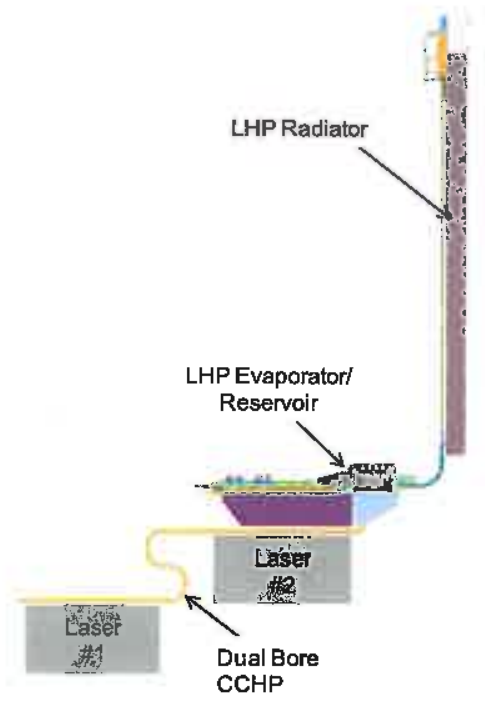

Figure 1. ATLAS LTCS concept

Table 1. ATLAS Laser Interface Temperature Limits

\begin{tabular}{|c|c|c|c|c|c|}
\hline $\begin{array}{c}\text { Cold Non-Operating } \\
\text { (Survival) } \\
\text { Temperature Limit } \\
\text { (deg C) }\end{array}$ & $\begin{array}{c}\text { Cold } \\
\text { Qualification } \\
\text { Temperature } \\
\text { Limit (deg C) }\end{array}$ & $\begin{array}{c}\text { Cold } \\
\text { Operating } \\
\text { Temperature } \\
\text { Limit (deg C) }\end{array}$ & $\begin{array}{c}\text { Hot } \\
\text { Operating } \\
\text { Temperature } \\
\text { Limit (deg C) }\end{array}$ & $\begin{array}{c}\text { Hot } \\
\text { Qualification } \\
\text { Temperature } \\
\text { Limit (deg C) }\end{array}$ & $\begin{array}{c}\text { Hot Non-Operating } \\
\text { (Survival) } \\
\text { Temperature Limit } \\
\text { (deg C) }\end{array}$ \\
\hline-10 & 10 & 15 & 30 & 35 & 40 \\
\hline
\end{tabular}

A design analysis shows that a single LTCS can satisfy the afore-mentioned temperature control requirements and control heater power constraints. However, it also reveals additional technical challenges. First, the LHP reservoir must operate at $-11.5^{\circ} \mathrm{C}$ in order to maintain the ATLAS at $+10^{\circ} \mathrm{C}$ at $250 \mathrm{~W}$, yielding an overall temperature drop of more than $20^{\circ} \mathrm{C}$. Such a temperature gradient decreases drastically during the spacecraft survival mode of operation, and the ATLAS temperature can drop below its minimum desirable temperature of $-2^{\circ} \mathrm{C}$ unless the LHP is shut down before that happens. During the spacecraft survival mode, the LTCS cannot run its software control algorithm and the LHP must rely solely on thermostats for shutdown. Figure 2(a) shows a shutdown heater circuit design where the shutdown heater is wired in series with two thermostats which close at $0^{\circ} \mathrm{C}$ and open at $5^{\circ} \mathrm{C}$. In this design, a direct spacecraft action is required, i.e. the spacecraft switch must be disabled when the LHP is operating and enabled when the lasers are turned off. Figure 2(b) illustrates a novel design which affords the spacecraft switch to be enabled at all times. In this design, the shutdown heater is wired in series with two reservoir thermostats and two CCHP thermostats. The reservoir thermostats (closed at $0^{\circ} \mathrm{C}$ and open at $+5^{\circ} \mathrm{C}$ )

2 
control the reservoir heater to prevent the circulation of ammonia. The CCHP thermostats (closed at $-2^{\circ} \mathrm{C}$ and open at $+3^{\circ} \mathrm{C}$ ) only enable the reservoir heater when the CCHP is cold. However, NASA Goddard Space Flight Center (GSFC) has not previously flown an LHP with such a shutdown heater circuit. In addition, the voltage of the LCTS power supplies can vary between $26 \mathrm{Vdc}$ and $34 \mathrm{Vdc}$ during the spacecraft life time. The reservoir control heater must be designed to provide $12.5 \mathrm{~W}$ at $26 \mathrm{Vdc}$. The control heater power increases to $21.4 \mathrm{~W}$ at $34 \mathrm{Vdc}$, which will ircrease the overshoot and undershoot of the reservoir temperature when the heater is cycling on and off, potentially impacting the ability of the LTCS to maintain the laser temperatures within the required $\pm 1^{\circ} \mathrm{C}$ accuracy, or worse, causing the LHP to go through repeated startup and shutdown cycles.

The feasibility of the shutdown heater design shown in Figure 2(b) and the ability of the LTCS to keep the ATLAS temperature within $\pm 1^{\circ} \mathrm{C}$ accuracy must be experimentally verified prior to proceeding to the final LTCS design and fabrication. A LTCS demonstration unit has been built, and tested in a thermal vacuum chamber to verify these performance characteristics. The following sections present details of the LTCS demonstration unit assembly, test setup, tests performed,

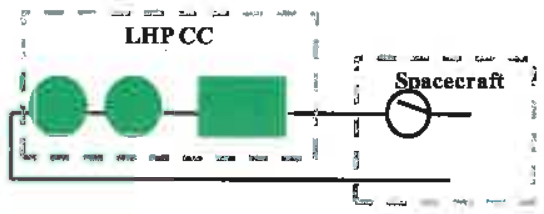

(a)

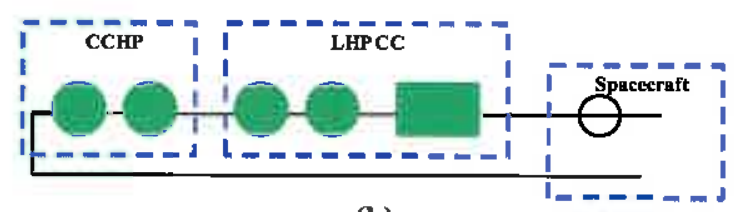

(b)

Figure 2. LHP Shutdown Heater Design

\section{LCTS Demonstration Unit and Test Setup}

Because of budget and schedule constraints, an engineering test unit of the ATLAS LCTS shown in Figure I was not built and tested to verify the LCTS operations mentioned above. Instead, a functionally equivalent LTCS demonstration unit was assembled using an existing CCHP and other existing LHP components. The CCHP shown in Figure 3 is a single bore pipe with an outer diameter and vapor core diameter of $12.83 \mathrm{~mm}$ and $7.87 \mathrm{~mm}$, respectively. The lengths of the evaporator, adiabatic and condenser sections are $127 \mathrm{~mm}, 305 \mathrm{~mm}$ and $127 \mathrm{~mm}$, respectively. It is capable of transporting $250 \mathrm{~W}$ of heat load. The evaporator and reservoir assembly of the LHP demonstration unit is the same as that used for NASA's orbiting GOES spacecraft, and is very similar se to that to be used in the ATLAS. The LHP was assembled and charged with ammonia at NASA GSFC. It can transport up to $1 \mathrm{KW}$ of heat. Major design parameters of the LHP are summarized in Table 2.

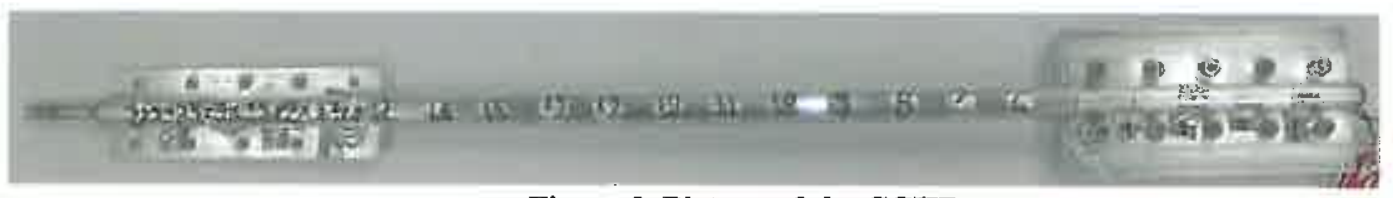

Figure 3. Picture of the CCHP

Table 2. Major Design Parameters of LTCS Demonstration Unit LHP

\begin{tabular}{|c|c|c|}
\hline Item & Material & Dimensions/Properties \\
\hline Evaporator & Aluminum & $29.98 \mathrm{~mm}$ O.D. $\times 24.13 \mathrm{~mm}$ I.D. $\times 305 \mathrm{~mm} \mathrm{~L}$ \\
\hline Primary Wick & Nickel & $\begin{array}{l}24.13 \mathrm{~mm} \text { O.D. } \times 8.1 \mathrm{~mm} \text { I.D.; pore radius }=0.8 \mu \mathrm{m} ; \\
\text { porosity }=0.6 \text {, permeability }=9 \times 10^{-14} \mathrm{~m}^{2}\end{array}$ \\
\hline Vapor Line & Stainless Steel & $6.35 \mathrm{~mm}$ O.D. $\times 4.93 \mathrm{~mm}$ I.D. $\times 1099 \mathrm{~mm} \mathrm{~L}$ \\
\hline Liquid Line & Stainless Steel & $6.35 \mathrm{~mm}$ O.D. $\times 4.93 \mathrm{~mm}$ I.D. $\times 1721 \mathrm{~mm} \mathrm{~L}$ \\
\hline Condenser & Stainless Steel & $5.56 \mathrm{~mm}$ O.D. $\times 4.52 \mathrm{~mm}$ I.D. $\times 5023 \mathrm{~mm} \mathrm{~L}$ \\
\hline Reservoir & Stainless Steel & Fluid volume $=401.5 \mathrm{cc}$ \\
\hline Working Fluid & Ammonia & Fluid inventory: 265 grams \\
\hline
\end{tabular}

Figures 4 and 5 show the isometric view and the side view, respectively, of the LTCS demonstration unit assembly along with a thermal mass that is made of aluminum block with a thermal capacitance of $23,362 \mathrm{~J} / \mathrm{K}$. The LHP reservoir, evaporator, condenser, vapor line, liquid line, and the thermal mass were secured to a frame structure using polymer standoffs to minimize conduction between the components and the frame structure.

3

American Institute of Aeronautics and Astronautics 
The LHP, CCHP and thermal mass were wrapped in 12-layer insulation to minimize radiation among the LTCS hardware and vacuum chamber, as shown in Figures 6 and 7. The two copper tubes shown in Figures 6 and 7 were the supply and return lines for the $\mathrm{GN}_{2}$ used to cool the LHP condenser. The $\mathrm{GN}_{2}$ flow was actively controlled via a solenoid valve to prevent excessive subcooling and possible freezing of the ammonia on the LHP condenser.

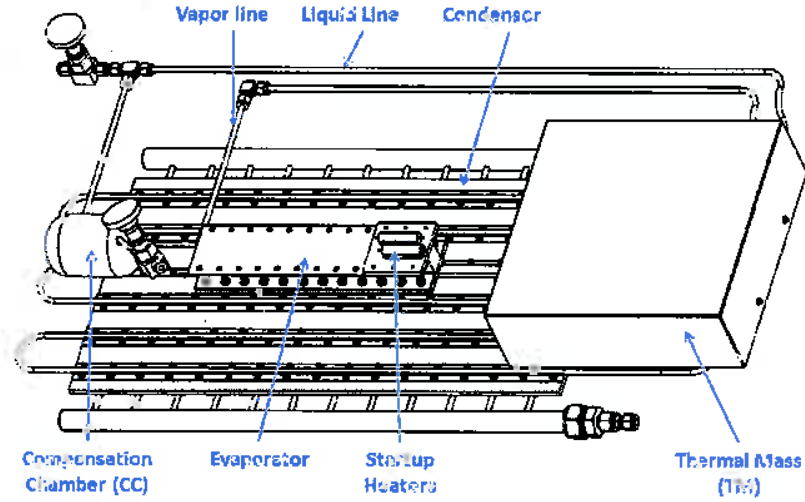

Figure 4. Isometric View of LTCS Demonstration unit

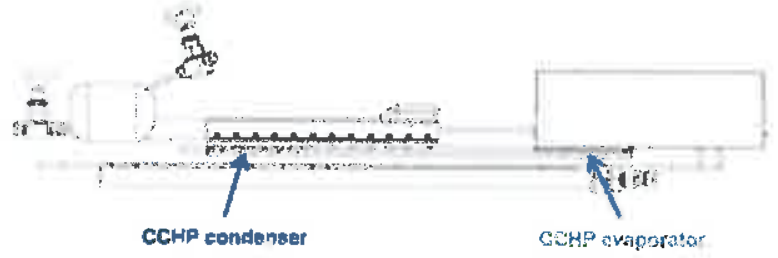

Figure 5. Side View of LTCS Demonstration unit

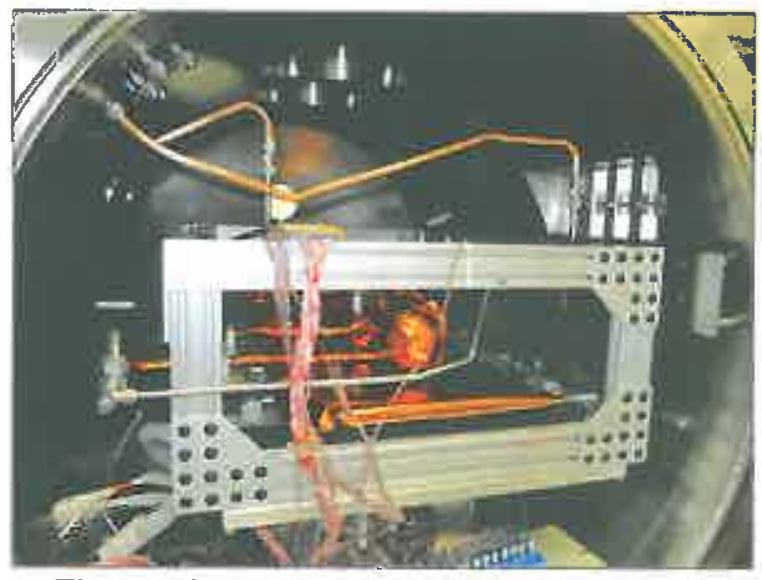

Figure 6. LTCS Demonstration Unit LHP Reservoir and Condenser Installed in Thermal Vacuum Chamber

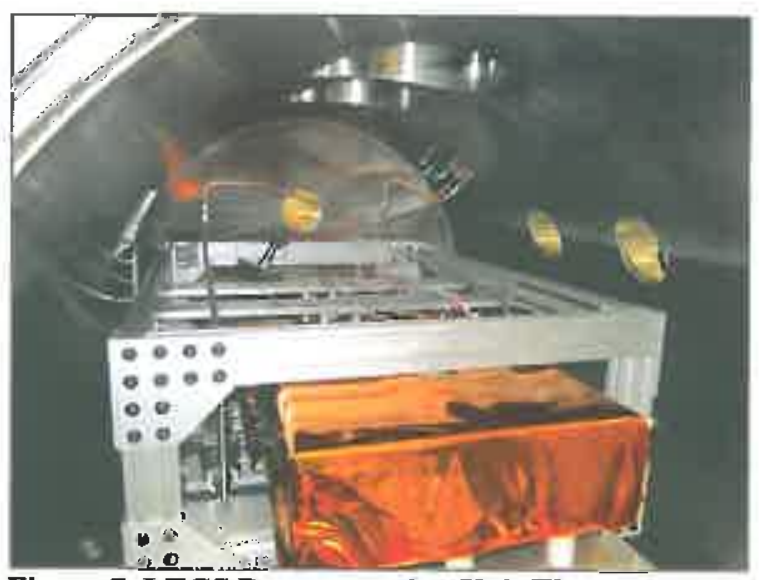

Figure 7. LTCS Demonstration Unit Thermal Mass Installed in Thermal Vacuum Chamber

Table 3 provides the flight and demonstration unit heater circuit specifications. The demonstration unit resistances do not match the flight heater resistances, but the flight and demonstration unit heater power levels were matched by adjusting the supply voltage to the heaters on the demonstration unit. Note that the power values shown for the control heater are for a single heater. In general, both control heaters will be enabled in flight, but they will have staggered set points so that only one heater will come on at a single time. As a worst-case scenario, both control heaters being powered simultaneously was considered in the 34 Vdc shutdown and temperature stability tests.

The temperature of the reservoir was regulated by two control heaters epoxied to the top two-thirds of the cylindrical section of the reservoir. Each Minco polyimide foil heater had a $25.4 \mathrm{~mm}$ by $76.2 \mathrm{~mm}$ footprint and a resistance of $39.2 \mathrm{ohm}$. The heaters were wired in series and software-controlled using a set point and a deadband in on-off mode. 
Table 3. Flight and Demonstration Unit Heater Circuit Specifications

\begin{tabular}{|l|c|c|c|c|c|c|c|}
\hline & \multicolumn{3}{|c|}{ Flight } & \multicolumn{4}{c|}{ Demonstration Unit } \\
\hline Heater type & $\begin{array}{c}\text { Power @ 26 } \\
\text { Vdc (W) }\end{array}$ & $\begin{array}{c}\text { Power @ 34 } \\
\text { Vdc (W) }\end{array}$ & $\begin{array}{c}\text { Heater } \\
\text { Resistance } \\
(\text { Ohm) }\end{array}$ & $\begin{array}{c}\text { Voltage at } \\
\text { Min. Power } \\
(\mathrm{V})\end{array}$ & $\begin{array}{c}\text { Current at } \\
\text { Min. } \\
\text { Power (A) }\end{array}$ & $\begin{array}{c}\text { Voltage at } \\
\text { Max. } \\
\text { Power (V) }\end{array}$ & $\begin{array}{c}\text { Current at } \\
\text { Max. } \\
\text { Power (A) }\end{array}$ \\
\hline Control & 12.5 & 21.4 & 78.5 & 31.3 & 0.40 & 41.0 & 0.52 \\
\hline Shutdown & 10.0 & 17.1 & 39.2 & 19.8 & 0.51 & 25.9 & 0.66 \\
\hline Start-up & 30.0 & 51.3 & 32.5 & 31.2 & 0.96 & 40.8 & 1.26 \\
\hline $\begin{array}{l}\text { Laser mass } \\
\text { simulator }\end{array}$ & $\begin{array}{c}10.0 \text { (start-up); } \\
125-250 \\
\text { (operational) }\end{array}$ & $\begin{array}{c}10.0 \text { (start-up); } \\
125-250 \\
\text { (operational) }\end{array}$ & 24.3 & 15.6 & 0.64 & 77.9 & 3.21 \\
\hline $\begin{array}{l}\text { Laser heat } \\
\text { pipe survival }\end{array}$ & 10.0 & 17.1 & 44.2 & 21.0 & 0.48 & 27.5 & 0.62 \\
\hline
\end{tabular}

The shutdown heater shown in Figure 2(b) will be wired in series with two reservoir thermostats and two CCHP thermostats for the flight LTCS. For testing of the demonstration unit, no thermostats were used. Instead, the shutdown heater was epoxied to the bottom one-thitd of the cylindrical section of the reservoir, adjacent to the two control heaters, and software was used to control the set points of relays for the reservoir and the CCHP. The set points for the reservoir relay and the CCHP relay were varied independently to simulate the open and closed status of the thermostats (e.g. the reservoir relay was closed at $0^{\circ} \mathrm{C}$ and open at $+5^{\circ} \mathrm{C}$ whereas the CCHP relay was closed at $-2^{\circ} \mathrm{C}$ and open at $+3^{\circ} \mathrm{C}$ ). Different combinations of the reservoir and $\mathrm{CCHP}$ relay set points were used in the demonstration unit tests to verify the feasibility of this control algorithm. The optimal values will be used for the thermostats on the flight LTCS.

Two Vishay Dale RER-type heaters, each with a fcotprint of $54 \mathrm{~mm}$ by $12.7 \mathrm{~mm}$ and a resistance of 16.2 ohm, served as start-up heaters. The heaters were mounted to an aluminum start-up heater plate that was mounted to the end of the LHP evaporator. Grafoil with ar. estimated conductance of $4000 \mathrm{~W} / \mathrm{m}^{2} /{ }^{\circ} \mathrm{C}$ was installed at the interface between the heaters and the heater plate and at the interface between the heater plate and LHP evaporator. The heaters were wired in series and software-controlled with on-off operation

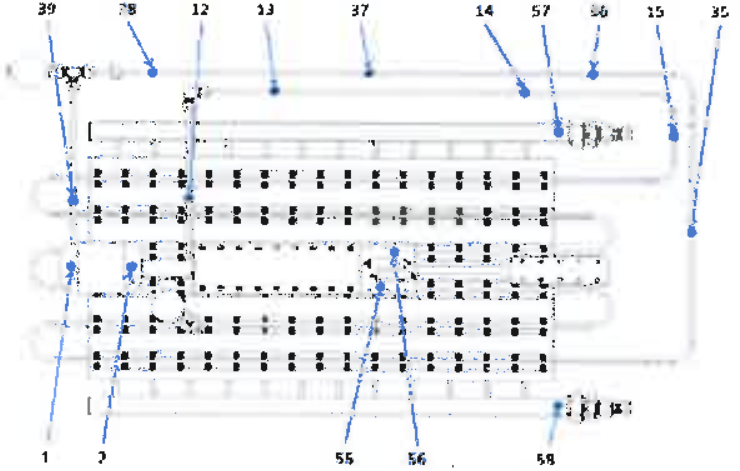

Figure 8. Thermocouple Locations on ITCS and Thermal Mass

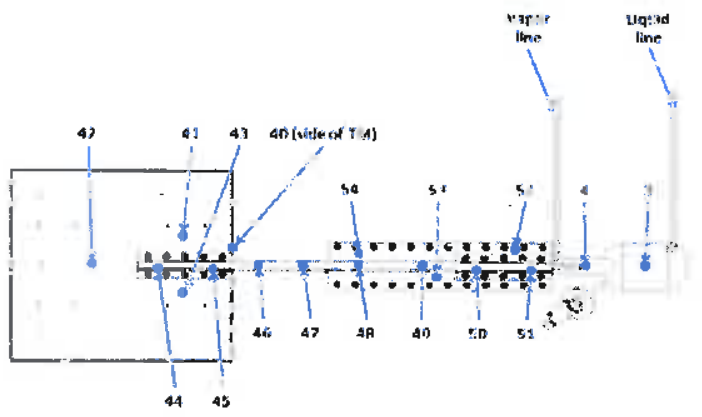

Figure 9. Thermocouple Locations on CCHP, LHP and Thermal Mass controlled by the operator.

Four cartridge heaters, each with a diameter of $9.53 \mathrm{~mm}$, length of $101.6 \mathrm{~mm}$ and resistance of $24.3 \mathrm{ohm}$, supplied heat to the thermal mass. The thermal mass heaters were inserted into $9.53 \mathrm{~mm}$ diameter by $104.8 \mathrm{~mm}$ long blind hcles drilled into the thermal mass. Two sets of two cartridge heaters were wired in series, with the resulting two sets of heaters wired in parallel. Sixty thermocouples were installed on the LTCS demonstration unit, thermal mass, and the GN2 cooling lines to monitor the temperatures during the thermal vacuum tests, as shown in Figures 8 and 9. A data acquisition system consisting of a data logger, a personal computer, and a screen monitors was used to collect, display, and store temperature and power data every 10 seconds. LabView software was used for the command and control of the test conditions. 
Several disparities exist between the LTCS demonstration unit and the flight unit:

1. The flight LTCS has redundant lasers whereas the LTCS demonstration unit has a single thermal mass. Because only one of the lasers will be operating at any time during flight, the demonstration unit can replicate the behavior of the flight LTCS adequately.

2. The flight CCHP condenser mounts directly to the LHP evaporator, whereas the demonstration unit CCHP condenser is mounted to an interface plate that is mounted to the LHP evaporator. This disparity results in a higher temperature drop across the CCHP/LHP interface in the demonstration unit. The primary effect of this difference on the LHP shutdown procedure is that the CCHP adiabatic section cools slower during shutdown on the demonstration unit than it is expected to on the flight unit.

3. The flight CCHP flanges that connect to the lasers are $50.8 \mathrm{~mm}$ by $355.6 \mathrm{~mm}$ and the flight CCHP flange to the LHP evaporator is $55.9 \mathrm{~mm}$ by $305 \mathrm{~mm}$. The demonstration unit CCHP flange that connects to the thermal mass is $40.6 \mathrm{~mm}$ by $130 \mathrm{~mm}$ and the demonstration unit CCHP flange that connects to the interface plate to the LHP evaporator is $40.6 \mathrm{~mm}$ by $130 \mathrm{~mm}$. The primary effect of this difference is a larger temperature drop between the thermal mass and CCHP evaporator and between the CCHP condenser and LHP evaporator, which does not significantly change the temperature stability of the demonstration unit but will lengthen the time period for the LHP shutdown.

4. The CCHP for the flight unit has two bores; the CCHP for the demonstration unit has a single bore. This disparity should have minimal effect on shutdown and stability testing.

5. The thermal capacitance of each of the flight lasers is $21,339 \mathrm{~J} / \mathrm{K}$, whereas the thermal capacitance of the demonstration unit thermal mass is $23,362 \mathrm{~J} / \mathrm{K}$. The slightly higher thermal capacitance of the demonstration unit thermal mass results in slightly slower temperature changes during testing.

6. The flight LTCS will reject heat via a radiator, whereas the LTCS demonstration unit rejects heat to a condenser that is convectively cooled by $\mathrm{GN}_{2}$. The primary effect of this disparity is that there are small fluctuations in the temperature of the ammonia leaving the LHP condenser resulting from the cycling of the valve that controlled $\mathrm{GN}_{2}$ flow to the coolant side of the condenser. The LHP radiator temperature should be more stable in flight.

7. The flight and demonstration unit vapor and liquid transport lines differ in length and inner diameter, which results in different ammonia pressure drops in the two units. This disparity should have minimal effect on shutdown and stability testing.

None of the disparities is expected to prevent the LTCS demonstration unit from adequately simulating the behavior of the flight LTCS, especially the ability of the thermostats to shut down the LHP during the survival mode.

\section{Tests Performed and Experimental Results}

The objectives of the ATLAS LTCS demonstration unit thermal vacuum testing were to: 1) validate the shutdown heater wired in series with thermostats shown in Figure 2(b) can effectively shut down the LHP at the minimum (26 Vdc) and maximum (34 Vdc) supply voltages; 2) verify that the LHP will not be shut down during the on-off cyclic operation of the control heaters at the minimum ( $26 \mathrm{Vdc}$ ) and maximum ( $34 \mathrm{Vdc}$ ) supply voltages; and 3) verify that the thermal mass can be maintained within an accuracy of $\pm 1^{\circ} \mathrm{C}$ during the on-off cyclic operation of the control heaters. These tests were to be performed after the LTCS had reached a steady or quasi-steady state. Because the LHP cannot perform its normal function until it has successfully started, start-up tests were also performed.

LHP Shutdown Test: Several LHP shutdown tests were conducted with various combinations of the thermal mass heat load, shutdown power, and temperature ranges for the reservoir relay and CCHP relay: 1) thermal mass heat load of $125 \mathrm{~W}$ and $250 \mathrm{~W}$; 2) shutdown power of $10 \mathrm{~W}$ and $17.1 \mathrm{~W}$ corresponding to the minimum and maximum shutdown power at $26 \mathrm{Vdc}$ and $34 \mathrm{Vdc}$ during the flight, respectively; 3) independent closed/open temperature ranges for the reservoir thermostats and CCHP thermostats using relay control. The baseline test was to have the reservoir thermostats closed at $0^{\circ} \mathrm{C}$ and open at $+5^{\circ} \mathrm{C}$, and to have the CCHP thermostats closed at $-2^{\circ} \mathrm{C}$ and open at $+3^{\circ} \mathrm{C}$. Because of the differences in the thermal conductances between the thermal mass and the CCHP and between the 
CCHP and LHP evaporator for the flight unit and the demonstration unit, the closed/open temperature ranges will be different. The demonstration unit test was designed to validate the proposed shutdown methodology. Once the methodology is validated, the actual closed/open temperature ranges for the reservoir thermostats and CCHP thermostats can be finalized based on the performance characteristics of the delivered LTCS flight unit. For risk mitigation, the ICESat-2 Project will procure in advance multiple sets of thermostats with different closed/open temperature ranges to allow flexibility after the flight unit is delivered.

Figure 10 shows the results from the LHP shutdown test with the heaters enabled at their $26 \mathrm{Vdc}$ power levels. Prior to the shutdown test, the LHP was running steadily with $250 \mathrm{~W}$ heat load applied to the thermal mass and with the reservoir temperature controlled at $-22^{\circ} \mathrm{C}$ using a deadband of $\pm 0.5^{\circ} \mathrm{C}$. The thermal mass average temperature was $+30.5^{\circ} \mathrm{C}$ with fluctuations of about $\pm 0.1^{\circ} \mathrm{C}$ resulting from the reservoir temperature fluctuations. The shutdown test started by disabling the thermal mass and the reservoir control heaters. In theory, the LHP will be shut down when the reservoir temperature exceeds the thermal mass temperature. Because of the large temperature difference between the thermal mass and the LHP evaporator $\left(-50^{\circ} \mathrm{C}\right)$, the thermal mass continued to dissipate its stored heat to the LHP and its temperature continued to decrease after the heat load was removed. The average rate of heat removal from the thermal mass was 193 $\mathrm{W}$, as indicated by a $20.8^{\circ} \mathrm{C}$ drop in thermal mass temperature before the shutdown heater was powered at 16:37. In this test, the closed/open temperature ranges for the reservoir heater relay and CCHP heater relay were $\left(0^{\circ} \mathrm{C},+5^{\circ} \mathrm{C}\right)$ and $\left(-2^{\circ} \mathrm{C},+3^{\circ} \mathrm{C}\right)$, respectively. While the shutdown heater was powered, and thus supplying $10 \mathrm{~W}$ to the reservoir (until 17:29), the average rate of heat removal from the thermal mass decreased to $64 \mathrm{~W}$, with the thermal mass temperature stabilizing at $+1.2^{\circ} \mathrm{C}$ after the shutdown heater switched off. While the shutdown heater was powered, the reservoir, LHP evaporator and CCHP temperatures all rose until the shutdown heater switched off due to the reservoir reaching $+5^{\circ} \mathrm{C}$. Sinutdown of the LHP had two indicators: first, the rapid temperature increase of the liquid retum line (17:20) as warm liquid was pushed from the reservoir toward the condenser via the liquid return line, and second, the rise of the reservoir temperature above the thermal mass $\left(+1.2^{\circ} \mathrm{C}\right)$ and LHP evaporator $\left(+2.3^{\circ} \mathrm{C}\right)$ temperatures. The LHP was monitored for several hours after shutdown with the $\mathrm{GN}_{2}$ outlet of the condenser maintained at $50^{\circ} \mathrm{C}$; the LHP never restarted.

Figure 11 shows the results from another LHP shutdown test with the same test parameters as described above except that the shutdown heater power was $17.1 \mathrm{~W}$ (corresponding to the maximum voltage of $34 \mathrm{Vdc}$ during the flight). During near steady state operation before shutdown, the reservoir was controlled to $22^{\circ} \mathrm{C}$ using a deadband of $\pm 0.5^{\circ} \mathrm{C}$. Cycling

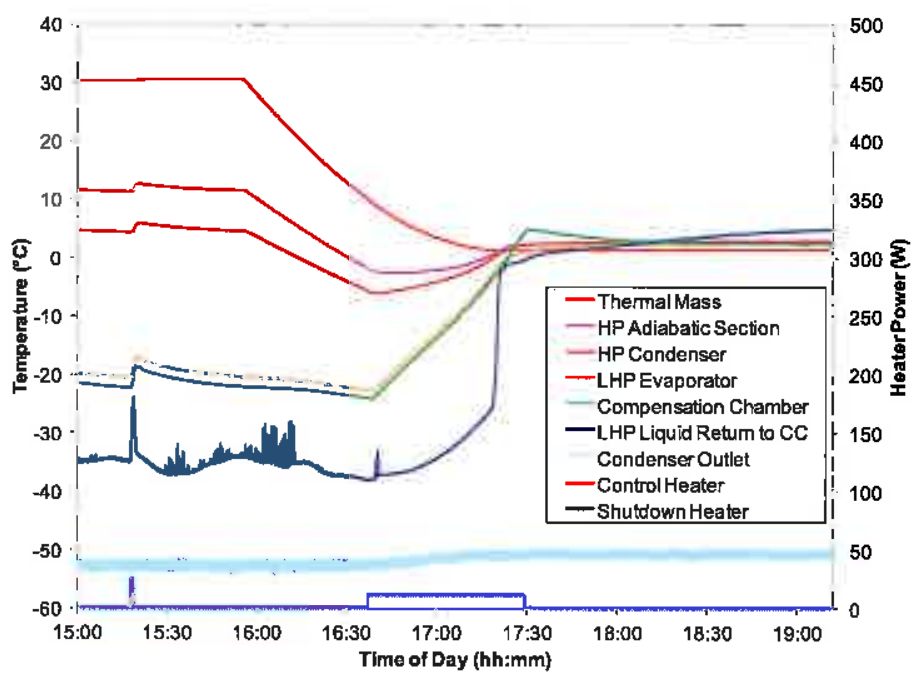

Figure 10. LHP Shutdown at 26 Vdc Power Levels

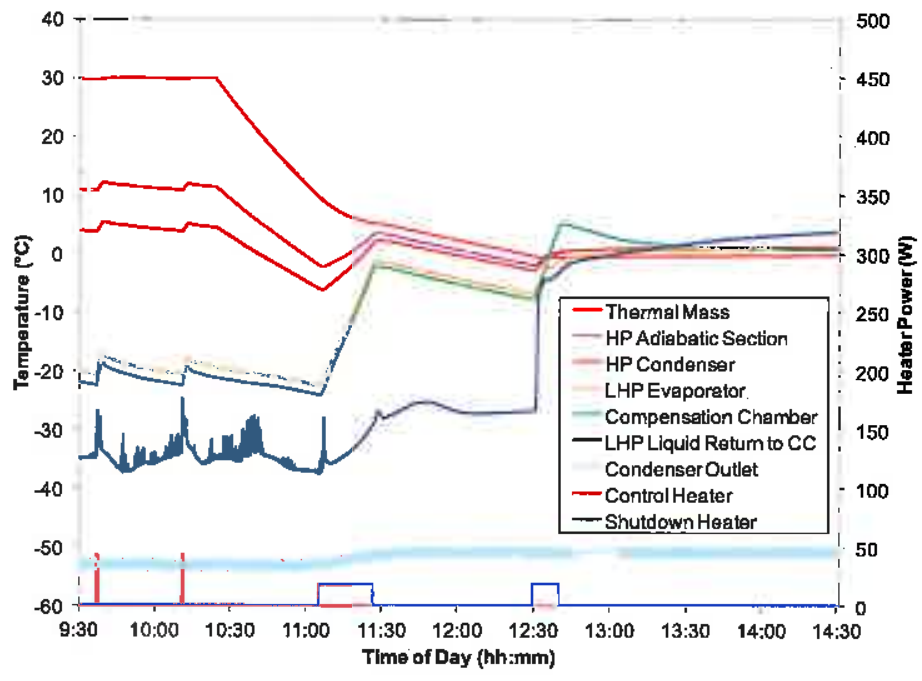

Figure 11. LHP Shutdown at 34 Vdc Power Levels 
of the control heater $(42.8 \mathrm{~W}$ based on both control heaters being powered simultaneously at their $34 \mathrm{Vdc}$ power levels) led to an average $2.2^{\circ} \mathrm{C}$ overshoot of the reservoir temperature. At near steady state operation with $250 \mathrm{~W}$ auplied to the thermal mass, the thermal mass average temperature was $30.1^{\circ} \mathrm{C}$, with fluctuations of about $\pm 0.15^{\circ} \mathrm{C}$ resulting from the reservoir temperature fluctuations when the control heater cycled on and off.

The thermal mass and reservoir control heaters were disabled to initiate the LHP shutdown at 10:24. After disabling the control and thermal mass heaters, the average rate of heat removal from the thermal mass was $193 \mathrm{~W}$, as indicated by a $20.3^{\circ} \mathrm{C}$ drop in thermal mass temperature before the shutdown heater was powered at $11: 05$. While the shutdown heater was powered on, and thus supplying $17.1 \mathrm{~W}$ to the reservoir (until 11:26), the average rate of heat removal from the thermal mass decreased to $87 \mathrm{~W}$, as indicated by the $4.7^{\circ} \mathrm{C}$ drop in temperature of the thermal mass during this time. After the shutdown heater switched off, the thermal mass temperature continued to decrease because the LHP continued to run. While the shutdown heater was powered on, the reservoir, LHP evaporator and CCHP temperatures all rose until the shutdown heater switched off due to the CCHP reaching $+3^{\circ} \mathrm{C}$. In the $34 \mathrm{Vdc}$ shutdown case, the higher power input to the reservoir caused the shutdown heater to be powered on for a shorter duration ( 21 minutes) than the powered on time of the shutdown heater in the $26 \mathrm{Vdc}$ case ( 52 minutes). In this test, the reservoir temperature never exceeded the thermal mass temperature before the shutdown heater was turned off. Thus, the LHP continued to operate and the LTCS continued to remove heat from the thermal mass.

At 12:29, the temperature of the CCHP fell below $-2^{\circ} \mathrm{C}$, thus closing the relay controlled by the CCHP temperature and powering on the shutdown heater because the relay controlled by the reservoir temperature remained closed (i.e., the reservoir temperature never reached its open temperature of $+5^{\circ} \mathrm{C}$ ). The shutdown heater applied power until the reservoir thermostat opened when the reservoir temperature exceeded $+5^{\circ} \mathrm{C}(12: 40)$. While the shutdown heater was powered for the second time, the average rate of heat removal from the thermal mass fell to $7 \mathrm{~W}$. During the second switch on of the shutdown heater, the LHP was shut down as indicated by the rapid temperature increase of the liquid return line (12:32) and the rise of the LHP reservoir temperature above the evaporator and thermal mass temperatures. The LHP was monitored for several hours after shutdown with the $\mathrm{GN}_{2}$ outlet of the condenser maintained at $-50^{\circ} \mathrm{C}$; the LHP never restarted.

Other shutdown tests were also conducted with different temperature ranges for the reservoir and CCHP relays, anid/or with $125 \mathrm{~W}$ to the thermal mass. In all tests, the LHP was completely shut down with the shutdown heaters being turned on once or twice.

Temperature Stability Test: The main purpose of the temperature stability test was to verify that the thermal mass could be maintained within an accuracy of $\pm 1^{\circ} \mathrm{C}$ during the on-off cyclic operation of the control heaters of $12.5 \mathrm{~W}$ $(26 \mathrm{Vdc})$ and $21.4 \mathrm{~W}(34 \mathrm{Vdc})$. There are two control heaters on the reservoir, and the set point temperatures for the two heaters are staggered by $0.5^{\circ} \mathrm{C}$. For risk mitigation, tests were also conducted on the demonstration unit to verify that the LHP would not be shut down during the simultaneous on-off cyclic operation of both control heaters at the maximum $(34 \mathrm{Vdc}$ ) supply voltage, i.e. at $42.8 \mathrm{~W}$ total heater power with both control heaters being turned on. In general, the higher the heat load to the thermal mass, the less its temperature will fluctuate with the on-off cycles of the reservoir control heater. Therefore, for ATLAS laser temperature stability, the best case scenario is with $250 \mathrm{~W}$ laser heat dissipation and $12.5 \mathrm{~W}$ reservoir heater power, whereas the worst case scenario is with $125 \mathrm{~W}$ laser heat dissipation and $42.8 \mathrm{~W}$ reservoir control heater power. The demonstration unit was tested with a heat load of $125 \mathrm{~W}$ and $250 \mathrm{~W}$, and reservoir control heater power of $12.5 \mathrm{~W}, 21.4 \mathrm{~W}$ and $42.8 \mathrm{~W}$.

Figure 12 shows the temperature profiles of the demonstration unit when $250 \mathrm{~W}$ was applied to the thermal mass and $12.5 \mathrm{~W}$ was supplied to the reservoir control heater. The reservoir set point temperature was $-22^{\circ} \mathrm{C}$ with a deadband of $\pm 0.5^{\circ} \mathrm{C}$. When the control heater was turned on, the reservoir temperature rose from $-22.4^{\circ} \mathrm{C}$ to $19.5^{\circ} \mathrm{C}$. This temperature fluctuation propagated from the reservoir through the evaporator and CCHP to the thermal mass with a diminishing effect. The thermal mass temperature fluctuated between $29.9^{\circ} \mathrm{C}$ and $30.1^{\circ} \mathrm{C}$, which was well within the required limit of $\pm 1^{\circ} \mathrm{C}$. 
Figure 13 shows the temperature profiles of the demonstration unit where $125 \mathrm{~W}$ was applied to the thermal mass and $42.8 \mathrm{~W}$ was supplied to the reservoir control heater. This test simulated the predicted worst case condition, i.e. the laser operates at the minimum power and the control heater power is at its absolute maximum assuming both control heaters are powered simultaneously at $34 \mathrm{Vdc}$. The test was run for more than 50 hours over the weekend, and Figure 13 shows the results over a 24 -hour period. With $42.8 \mathrm{~W}$ control heater power, the reservoir temperature fluctuated between $-22.5^{\circ} \mathrm{C}$ and $-19.0^{\circ} \mathrm{C}$ when the heater cycled off and on. The temperature fluctuation diminished gradually as it propagated from the reservoir via the evaporator and CCHP to the thermal mass. The thermal mass temperature varied between $4.2^{\circ} \mathrm{C}$ and $4.5^{\circ} \mathrm{C}$, and the fluctuation of $\pm 0.15^{\circ} \mathrm{C}$ was much less than the required temperature stability of $\pm 1^{\circ} \mathrm{C}$.

Other tests with $21.4 \mathrm{~W}$ of reservoir control heater power and with $125 \mathrm{~W}$ and $250 \mathrm{~W}$ to the thermal mass also demonstrated very similar temperature stability of the thermal mass. The ability of the reservoir control heater to maintain the thermal mass temperature within $\pm 1^{\circ} \mathrm{C}$ at $26 \mathrm{Vdc}$ and $34 \mathrm{Vdc}$ with heat loads of $125 \mathrm{~W}$ and $250 \mathrm{~W}$ to the thermal mass was therefore successfully verified. The LHP was never at risk of being shut down even in the worst case scenario where the control heater was at its maximum voltage of $34 \mathrm{Vdc}$ and the thermal mass was at its minimum power of $125 \mathrm{~W}$.

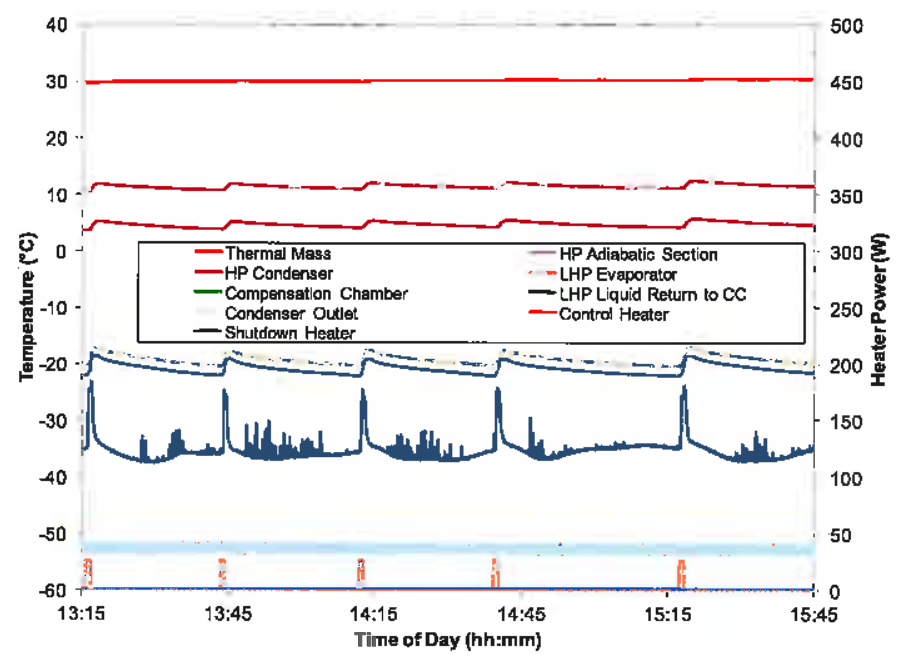

Figure 12. Temperature Stability Test with 250W Heat Load and 12.5W Control Heater Power

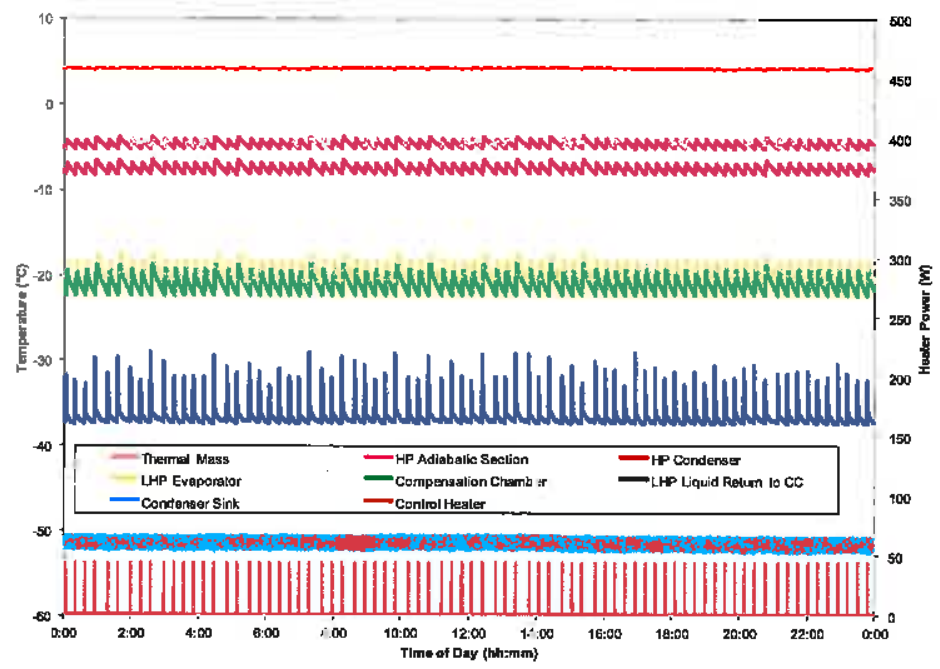

Figure 13. Temperature Stability Test with $125 W$ Heat Load and 42.8W Control Heater Power

Start-up Test: An LHP must start successfully before it can be placed for service. Start-up represents one of the most complex transient phenomena in the LHP operation. The common method to ensure a high probability of successful start-up, which is adopted by the ATLAS LTCS, is to flood the entire LHP with liquid prior to start-up and use a start-up heater to provide a high heat flux to initiate nucleate boiling. There are two start-up heaters on the LTCS LHP evaporator; each provides $15 \mathrm{~W}$ at $26 \mathrm{Vdc}$. During the flight, the ATLAS lasers will not be turned on until the LHP has started successfully and the LHP vapor temperature reaches the laser operating temperature $\left(15^{\circ} \mathrm{C}\right.$ to $30^{\circ} \mathrm{C}$ ). In general, the smaller the start-up power and the lower the initial evaporator temperature, the more difficult it is for the LHP to start $[3,14]$. In the demonstration unit testing, start-up tests were conducted with the start-up heater at $30 \mathrm{~W}$ total (both heaters at $26 \mathrm{Vdc}$ ) and $51 \mathrm{~W}$ total (both heaters at $34 \mathrm{Vdc}$ ), and with the initial L.HP evaporator and reservoir temperatures between $5^{\circ} \mathrm{C}$ to $22^{\circ} \mathrm{C}$. All start-up tests were successful and no problems were encountered. Results of two start-up tests are presented below. 
Figure 14 shows the temperature profiles for start-up test with $51 \mathrm{~W}$ applied to the evaporator. The initial temperatures of the thermal mass, evaporator, CCHP, and condenser sink were $8{ }^{\circ} \mathrm{C}, 10^{\circ} \mathrm{C}, 10{ }^{\circ} \mathrm{C}$, and $-50{ }^{\circ} \mathrm{C}$, respectively. The reservoir temperature was controlled at $12^{\circ} \mathrm{C}$ with $21.4 \mathrm{~W}$ of control heater power. The period before 10:40 was referred to as pressure priming whose purpose was to ensure that the entire LHP was completely filled with liquid. At 10:40, the start-up heaters were turned on to supply $51 \mathrm{~W}$ to the evaporator. The evaporator temperature continued to tise, and the loop started at 10:42 as indicated by the rise of the vapor line temperature above the reservoir temperature and the drop of the liquid line temperature. Part of the heat applied to the evaporator went to heat the thermal mass, and the remaining heat was used to vaporize the liquid inside the evaporator to sustain the flow circulation. After a successful start-up was verified as evidenced by a continuing decrease of the liquid line temperature, the thermal mass heater was turned on with a heat load of $250 \mathrm{~W}$ (10:58). With a much larger heat load, the thermal mass temperature rose more quickly. After the thermal mass temperature exceeded the CCHP temperature at $11: 20$, the $250 \mathrm{~W}$ heat load applied to the thermal mass began to flow to the LHP. The periodic rises of the liquid line temperature between 11:00 and 11:20 was due to the turning on of the reservoir control heater, which pished warm liquid from the reservoir toward the condenser via the liquid line. The magnitude of the liquid line temperature rise would decrease when the net heat load to the LHP increased, eg. when more and more of the heat lcad applied to the thermal mass flowed to the evaporator. This is clearly seen in Figures 12 and 13 during the steady state.

Figure 15 show the temperature profiles for another start-up test under the same condition described above except that the start-up heater power was reduced to $30 \mathrm{~W}$ total (both start-up heaters were turned on at $26 \mathrm{Vdc}$ ). The loop was pressure primed prior to $9: 40$, at which time the two start-up heaters were turned on. The vapor line temperature rose above the reservoir temperature at 9:46, signaling the start of the liquid vaporization. With a smaller heat load to the evaporator, the mass flow rate inside the LHP was slower and the cold liquid from the condenser did not reach the inlet of the reservoir until 10:03. With the assurance of the flow circulation and a successful start-up, a heat load of $250 \mathrm{~W}$ was applied to the thermal mass at 10:20. The temperature of the thermal mass exceeded the CCHP temperature at

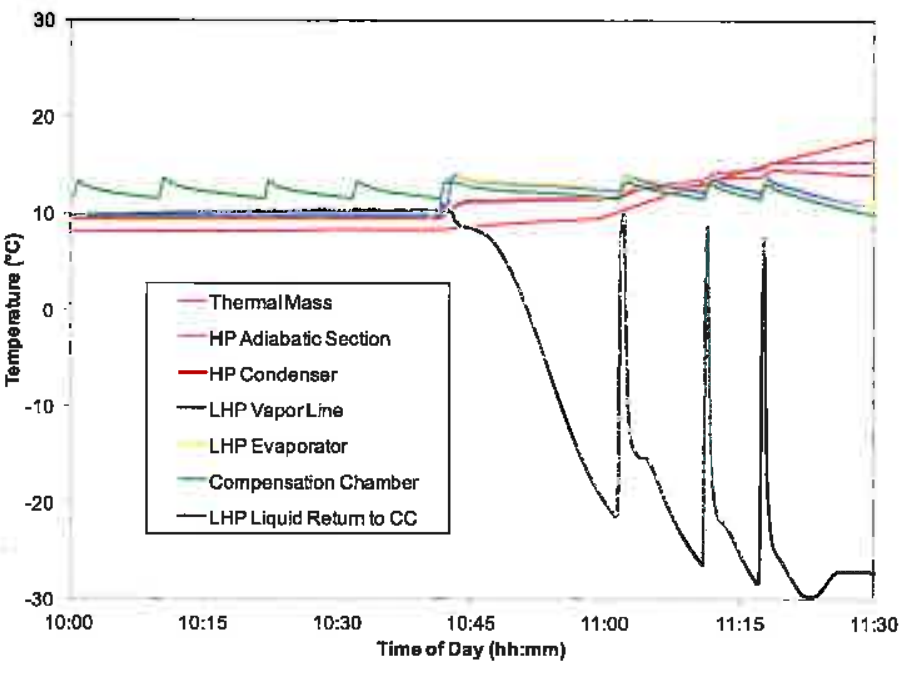

Figure 14. Start-up with 51W

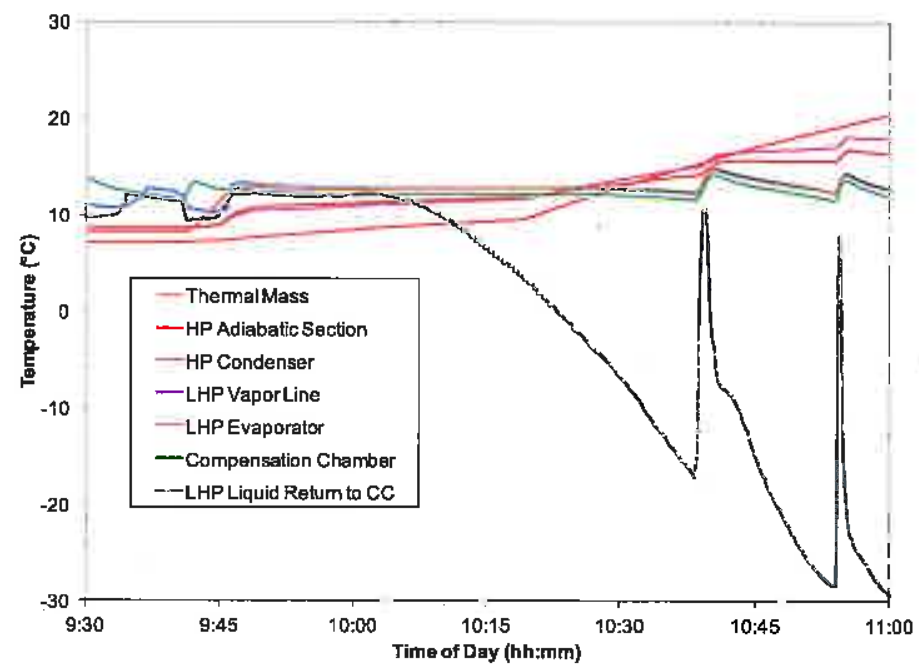

Figure 15. Start-up with 30W thermal mass to the evaporator. The LHP operation continued to move toward a steady state. 


\section{Summary and Conclusions}

A demonstration unit of the ATLAS LTCS was designed to replicate comparable operating characteristics of the flight LTCS. Although the demonstration unit's design and components were not identical to those of the flight LTCS, the primary result of these differences was a larger temperature gradient between the thernal mass and LHP evaporator, which should have little effect on the validity of the shutdown and temperature stability results presented in this paper.

The novel LHP shutdown heater configuration was tested while replicating the heater powers when the bus voltage was $26 \mathrm{Vdc}$ (minimum) and $34 \mathrm{Vdc}$ (maximum). Tests conducted with various combinations of the thermostat on-off temperature range, heat load to the thermal mass, and shutdown heater voltage were all successful. The temperature stability of the LTCS was demonstrated with the maximum possible power input to the control heater and the minimum operational power from the thermal mass. The LTCS demonstration unit was run for more than 50 hours under this worst-case operating condition. The high power into the reservoir caused the reservoir temperature to fluctuate, which in turn caused a temperature fluctuation of the thermal mass. The magnitude of the temperature fluctuation of the thermal mass was well within the stability requirement of $\pm 1^{\circ} \mathrm{C}$ in all tests. At no point during testing did the control heater shut down the LHP despite the worst case operation conditions. All of the LHP start-up tests with the demonstration unit were successful, including the worst case low start-up heater power and low initial evaporator/reservoir temperatures.

In summary, Tests conducted with the demonstration unit encompassed the entire envelope conditions expected during the flight and beyond. All tests were successful. Based on the tests performed in this study, it is expected that, during the flight, the LHP will have a high probability to start successfully, the LTCS can meet the temperature stability of $\pm 1^{\circ} \mathrm{C}$ required by the lasers, and the shutdown heater circuit and shutdown procedure will operate reliably.

\section{References}

1. Faghri, A., Heat Pipe Science and Technology, Taylor and Francis, New York, New York, 1995.

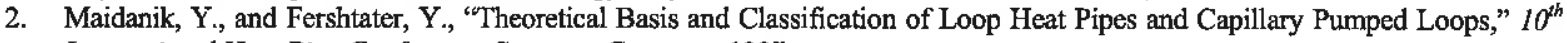
International Heat Pipe Conference, Stuttgart, Germany, 1997.

3. Ku, J., "Operating Characteristics of Loop Heat Pipes," SAE Paper No. 1999-01-2007, $29^{\text {th }}$ International Conference on Environmental Systems, Denver, Colorado, July 12-15, 1999.

4. Maidanik, Y, "Loop Heat Pipes - Theory, Experimental developments and Application," 13 $3^{\text {th }}$ International Heat Pipe Conference, Sydney, Australia, August 9-13, 2006.

5. Nikitkin, M. N., Kotlyarov, E. Y. and Serov, G. P., "Basics of Loop Heat Pipe Temperature Control", Paper No. 1999-01-2012, $29^{\text {th }}$ International Conference on Environmental Systems, Denver, Colorado, July 12-15, 1999.

6. Ku, J., "Methods of Controlling the Loop Heat Pipe Operating Temperature," SAE Paper No. 2008-01-1998, 38 International Conference on Environmental Systems, San Francisco, California, June 30 - July 2, 2008.

7. Goncharov, K., Nikitkin, M., Fershtater, Y., and Maidanik, Y., 'Loop Heat Pipes in Thermal Control system for OBZOR Spacecraft, $25^{\text {th }}$ International Conference on Environmental Systerns, San Diego, Califormia, July 10-13, 1995.

8. Grob, E., Baker, C., and McCarthy, T., "Geoscience Laser Altimeter System (GLAS) Loop Heat Pipe: An Eventful First Year On-Orbit", Paper No. 2004-01-2558, $34^{\text {th }}$ Intemational Conference on Environmental Systems, Colorado Springs, Colorado, July 19-22, 2004.

9. Grob, E., "Performance of the GLAS Loop Heat Pipes -7 Years in Orbit", Paper No. AIAA-2010-6029, 40" International Conference on Environmental Systems, Barcelona, Spain, July 11-15, 2010.

10. Choi, M., "Thermal Assessment of Swift BAT Instrument Thermal Control System in Flight", Paper No. 2005-01-3037, 35 International Conference on Environmental Systems, Rome, Italy, July 11-14, 2005.

11. Choi, M., "Thermal Assessment of Swift Instrument Module Thermal Control System during First 2.5 Years in Flight," Paper No. 2007-01-3083, 37t International Conference on Environmental Systems, Chicago, Illinois, July 9-12, 2007.

12. Rodriguez, J. I., "Thermal Design of the Tropospheric Emission Spectrometer Instrument", SAE Paper No. 2000-01-2274, 30" International Conference on Environmental Systems, Toulouse, France, July 10-13, 2000.

13. Rodriguez, J. I., Na-Nakompanom, A., Rivera, J., Mireles, V. and Tseng, H., "On-Orbit Thermal Performance of the TES Instrument - Three Years in Space," SAE Paper No. 2008-01-2118, 38 th International Conference on Environmental Systems, San Francisco, California June 30 - July 2, 2008.

14. Ku, J., Ottenstein, L., Rogers, P., and Cheung, K., "Investigation of Low Power Operation in a Loop Heat Pipe," SAE Paper No. 2001-01-2192, $3 I^{\text {st }}$ International Conference on Environmental Systems, Orlando, Florida, July 9-12, 2001. 